\title{
Clinical Training for Medical Physicist: Implementation Experience in Bangladesh
}

\author{
Kamila Afroj Quadir \\ Institute of Nuclear Medicine and Ultrasound, Bangladesh Atomic Energy Commission, Dhaka, Bangladesh
}

Address For Correspondence: Prof. Kamila Afroj Quadir, National Institute of Nuclear Medicine \& Allied Sciences, BAEC, BSM Medical University Campus, Shahbagh, Dhaka, Bangladesh. Email: q.kamila@gmail.com

\begin{abstract}
It is very important that the medical physicists working in hospitals need to be clinically trained.

Bangladesh was the first RCA member to implement clinical training programme based on the guide-book for medical physicists specializing in nuclear medicine developed by International Atomic Energy Agency. A National Program was established and Bangladesh Medical Physics Association agreed to be the Professional Body for accreditation. The 2 years pilot to test the effectiveness of the guidebook was successfully finished. The Clinical Training for medical physicists specializing in nuclear medicine improved the capabilities of the Physicits'. A sustainable accreditation structure is in place. The objective of the program was to set up an infrastructure to operate an independent and sustainable accreditation programme that is recognized by all in Bangladesh and to test out the effectiveness of the guidebook in providing clinical training to medical physicists specializing in nuclear medicine.
\end{abstract}

Key words: Medical physicists, Clinical Training

\section{INTRODUCTION}

The practice of residency, and the need thereof, is well understood in the physician circle. Since human lives are involved, just a formal degree is not considered sufficient to allow graduates to deal directly with patients. Therefore fresh graduates entering the profession of medical practice need to be clinically trained under supervision for a period of time before they are allowed to practice independently.

The human healthcare is evolving, both from a diagnostic and therapeutic perspective, it is increasingly becoming a multi-disciplinary endeavor. Actions of personnel from disciplines other than physician have direct or indirect impact on the wellbeing of the patients. Medical physicists are increasingly becoming a part of the clinical environment, especially in nuclear medicine, radiation oncology and diagnostic radiology. Therefore these personnel must also be clinically trained, even after they have a formal degree, with the same vigor as is required by physicians. This trend is already prevalent in developed countries.

With a view to facilitate and expedite the implementation of clinical training of medical physicists among the Regional Cooperative Agreement (RCA) member nations" in the Southeast Asia Region, International Atomic Energy Commission (IAEA) took the initiative of developing three separate guide-books for medical physicist who specialize and operate in a clinical environment in Nuclear Medicine (1), Radiation Oncology (2) and Diagnostic Radiology (3).

The idea is that each member country will develop its own sustainable accreditation programme so that medical physicists who are involved in the clinical environment and specializing in nuclear medicine, radiation oncology and diagnostic radiology are clinically competent before they are allowed to independently operate and interact with patients.

Bangladesh was the first RCA member to implement clinical training programme based on the guide-book for medical physicists specializing in nuclear medicine. The objective of the program was to set up of an infrastructure to operate an independent and sustainable accreditation programme that is recognized by all in Bangladesh and to test out the effectiveness of the guidebook in

\footnotetext{
- RCA Asia-Pacific member states are Bangladesh, China, India, Indonesia, Japan, Republic of Korea, Malaysia, Mongolia, Myanmar, Pakistan, Philippines, Singapore, Sri Lanka, Thailand, and Vietnam.
} 
providing clinical training to medical physicists specializing in nuclear medicine.

\section{METHODS}

To ensure sustainability of the accreditation programme, the guide books outline the structure for the governance of the clinical training programmes. The proposed general guidance is as follows:

The participants in the clinical programme are the Residents. They are mentored by Clinical Supervisors who is a suitably qualified and experienced medical physicist specialized in nuclear medicine and is working in the same department as the Residents. They have a pivotal role in ensuring the success of the clinical training of a Resident.

The set-up also calls for Support Group that is made up of individuals who agree to assist with Resident training. The support group may include nuclear medicine physicians, nuclear medicine physicists and personnel from educational institutions.

The responsibility for setting the professional standards required for defining competencies and providing professional support for the programme should fall on a Professional Body. This professional body would normally have overall responsibility of the assessment processes.

A National Programme Coordinator is proposed to facilitate the implementation of the project. To supervise the National Programme Coordinator, a National Steering Committee comprising of the Professional Body and representatives from relevant interest groups and stakeholders is proposed. The National Steering Committee is to be responsible for maintaining standards in the programme by ensuring that guidelines for participation are strictly followed by Departments and Residents.

The apex of the proposed structure is the National Responsible Authority that is to provide formal recognition of the qualification provided by the programme. It is responsible for forming the National Steering Committee and appointing the National Programme Coordinator. The National
Responsible Authority delegates authority of overseeing the programme to the National Steering Committee.

To test the effectiveness of the IAEA-TCS-50 (1) guide-book in providing clinical training to medical physicists specializing in nuclear medicine, the programme needed to be completed in the two year as designated in the IAEA-TCS guide books. During this period the Residents are expected to go through the entire IAEA-TCS-50 guide book consisting of 11 modules and 57 sub-modules. The Residents are first to observe new task a number of times, then the Resident are to cover the background knowledge. After acquiring background knowledge the Residents should perform the tasks supervised in routine duties. The Residents would then be assessed performing the task supervised by the Supervisor. After reviewing the tasks by the Residents and Supervisors, the Residents would be allowed to perform the task unsupervised and the Residents would then be assessed performing task unsupervised. Finally the Residents would perform tasks unsupervised as part of their clinical duties.

\section{Bangladesh Implementation Experience}

The Accreditation Structure: Bangladesh Atomic Energy Commission took the overall responsibility for the programme as the National Responsible Authority. An eight member National Steering Committee was formed comprising of the Director of Institute of Nuclear Medicine and Ultrasound, two Directors from two Nuclear Medicine Centers, The Director of International Affairs Division of Bangladesh Atomic Energy Commission, the Supervisors, the Chairman of Department of Biomedical Physics and Technology, President of Bangladesh of Medical Physics Association (BMPA) and the National Programme Coordinator of the project.

Bangladesh Medical Physics association (BMPA) was ideally suited to be the Professional Body that can provide accreditation (certification) to the competencies acquired by the Residents. As BMPA is affiliated to the International Organization for Medical Physics (IOMP), they have been considered as best positioned to provide accreditation on the long run in order to ensure that 
a high level of professional competency is maintained. A proposal for accreditation was accepted by BMPA.

\section{THE PILOT}

Four (4) Residents participated from three (3) Centers of Nuclear Medicine: Institute of Nuclear Medicine and Ultrasound (INMU) (2 Residents), Centre for Nuclear Medicine \& Ultrasound (CNMU), Dhaka (1 Resident) and CNMU Mitford (1 Resident). Two (2) Clinical Supervisors had the responsibility of two (2) Residents each. The Course was run at the Institute of Nuclear Medicine and Ultrasound (INMU) as the base Institute.

The Residents were required to make presentation on most of the modules. The sub-modules where the facilities were absent were excluded. Each Resident had to submit three (3) assignments in suitable topics. They had to present these assignments in National/ International / Departmental seminars or conferences. The Residents had to maintain a portfolio where Supervisor assessed Residents' competency level and where they also kept all necessary "Documents of Evidence" of their presentation, assignment, research work, assessment schedule, progress reports, level of competency achieved in knowledge and practical base.

To ensure the success of the pilot programme and to ensure that standards are being maintained, an External Coordinator monitored the progress of Residents and the programme in general. They worked closely with the National Programme Coordinator and National Steering Committee to ensure the smooth operation and success of the programme. The lead Country Coordinator, Australia, played this role.

There were also External Reviewers who monitored the progress of individual Residents and review their work plan or items of assessment. Two IAEA experts visited Bangladesh to review the progress of the Residents, provide assistance for better understanding of the TCS 50 material. One of the external reviewers also acted as final examiner.
In the absence of sufficient resources within the country, the role of Support Group was also provided by IAEA in the form of expert physicists who conducted two 4-days workshops, over the span of one and a half year, for better understanding of the course materials.

All residents completed 66 knowledge based competencies. Out of the 63 practical based competencies, 59 were completed. The rest could not be completed due to lack of physical facilities. The final examination consisted of a three hour written examination followed by practical and oral examination with an external examiner from IAEA.

The two year programme started in January 2011 and was successfully finished on time in December 2012.

BMPA has formed an accreditation board to assess the residents and deliver certificate of accreditation. It has been decided by the accreditation board that the residents will be assessed by appearing in a certification examination on the basis of the IAEA TCS-50 (1) guidelines in mid June, 2013.

\section{FUTURE CHALLENGES}

A distinction needs to be made between formal education in Medical Physics and Clinical training and Accreditation programme. Universities do provide specialized courses in medical physics, and there would obviously be variation in standards, however, irrespective of the quality of formal education, the graduating students would still be inadequate for practical clinical application. In the hospital environment, whether providing diagnostic or therapeutic service, patients are being dealt with and therefore there is a heightened sensitivity. Structured clinical in-service training programme for medical physicists is therefore essential on the long run.

In Bangladesh, the private sector healthcare providers are making significant progress and the demand for clinically qualified medical physicists specialized in the nuclear medicine, radiation oncology and diagnostic radiology is becoming 
more pronounced like other developing countries. Therefore a need for National Standard for clinical practitioners is all the more urgent. In the absence of such standards, patients may be exposed to undue risks as the increasing complexity of both diagnostic and treatment facilities as well as heightened awareness of radiation protection and safety standards in the clinical environment as the number of radiotherapy, radiology and nuclear medicine department are increasing day by day.

A sustainable accreditation structure is in place. Going forward, similar programme for radiation oncology and diagnostic radiology needs to be tested. The next and the most crucial step would be to establish and sustain a National Accreditation Programme for medical physicists' specializing in nuclear medicine, radiation oncology and diagnostic radiology under the auspices of BMPA.

\section{CONCLUSION}

The Clinical Training Programme for medical physicists specializing in nuclear medicine has improved the capabilities of the Residents (Physicists) in the field of nuclear medicine and it is being reflected in their level of self-confidence. They are being appreciated by the Physicians and others colleagues. Similar programme for radiation oncology and diagnostic radiology are expected to yield similar results.

The career success of the first batch of Residents in nuclear medicine has drawn significant attention and interest. Enquires from young medical physicists, not only those specializing in nuclear medicine but also working in diagnostic radiology and radiation oncology are being received. The crucial task of establishing a sustainable accreditation programme for medical physicists working in clinical environment needs to be addressed at BMPA for all sub-specializations. It is expected that in future such accreditation will become a basic requirement for medical physicist operating in a clinical environment. This is seen as vital in raising the standard of the practice of medical physics in Bangladesh.

\section{ACKNOWLEDGMENT}

This work was carried out within the RCA Project 'Strengthening of Medical Physics Through Education and Training (RAS/6/038)" of International Atomic Energy Agency (IAEA).The author would like to thank IAEA for giving the opportunity to run this Project and wish to acknowledge Dr. Stig Palm, Dr. Donald Mclean, Dr. A. Meghzifene of IAEA for the support given to Bangladesh. The author also wants to thank Professor Brian Thomas, Dr. Roger Fulton, Dr. Bertil Axelsson, for their constant support in carrying out the course and examination process.

\section{REFERENCES:}

1. Clinical Training of Medical Physicists Specializing in Nuclear Medicine; Training Course Series (TCS) 50, IAEA, Vienna, 2011

2. Clinical Training of Medical Physicists Specializing in Radiation Oncology; Training Course Series (TCS) 37, IAEA, Vienna, 2009

3. Clinical Training of Medical Physicists Specializing in Diagnostic Radiology; Training Course Series (TCS) 47, IAEA, Vienna, 2010 